\title{
Neuronal Death and Blood-Brain Barrier Breakdown after Excitotoxic Injury Are Independent Processes
}

\author{
Zu-lin Chen, ${ }^{1,2}$ Justin A. Indyk, ${ }^{1,2,3}$ Thomas H. Bugge, ${ }^{4}$ Keith W. Kombrinck, ${ }^{4}$ Jay L. Degen, ${ }^{4}$ and \\ Sidney Strickland ${ }^{1,2}$ \\ ${ }^{1}$ Department of Pharmacology, ${ }^{2}$ Program in Genetics, and ${ }^{3}$ Medical Scientist Training Program, University at Stony Brook, \\ Stony Brook, New York 11794-8651, and "Division of Developmental Biology, Children's Hospital Research Foundation, \\ Cincinnati, Ohio 45229
}

\begin{abstract}
Neuronal damage in the CNS after excitotoxic injury is correlated with blood-brain barrier (BBB) breakdown. We have used a glutamate analog injection model and genetically altered mice to investigate the relationship between these two processes in the hippocampus. Our results show that BBB dysfunction occurs too late to initiate neurodegeneration. In addition, plasma infused directly into the hippocampus is not toxic and does not affect excitotoxin-induced neuronal death. To test plasma protein recruitment in neuronal degeneration, we used plasminogen-deficient $\left(\mathrm{plg}^{-/-}\right.$) mice, which are resistant to excitotoxin-induced degeneration. Plasminogen is produced in the hippocampus and is also present at high levels in plasma,
\end{abstract}

allowing us to determine the contribution of each source to cell death. Intrahippocampal delivery of plasminogen to $\mathrm{plg}^{-1-}$ mice restored degeneration to wild-type levels, but intravenous delivery of plasminogen did not. Finally, although the neurons in $\mathrm{plg}^{-/-}$mice do not die after excitotoxin injection, BBB breakdown occurs to a similar extent as in wild-type mice, indicating that neuronal death is not necessary for BBB breakdown. These results indicate that excitotoxin-induced neuronal death and BBB breakdown are separable events in the hippocampus.

Key words: plasminogen; tPA; neurodegeneration; bloodbrain barrier; kainate; hippocampus; mouse
Neuronal cell death is a hallmark of many neurodegenerative disorders, such as Alzheimer's disease, Parkinson's disease, and Huntington's disease. Loss of brain function caused by neurodegeneration affects millions of people each year and is a major cause of long-lasting disability. Despite the enormity of the problem, the few therapies that attempt to retard the progression of neurodegeneration in those disorders are not very effective (Shoulson, 1998). Therefore, a better understanding of the mechanisms of neurodegeneration is a critically important medical issue.

Recent studies on the mechanisms of neurodegeneration have revealed that neuronal death is often initiated by overexcitation of neurons because of the extracellular accumulation of high levels of the excitatory amino acid glutamate (Meldrum and Garthwaite, 1990; Coyle and Puttfarcken, 1993; Lipton and Rosenberg, 1994). This mechanism for neurodegeneration has been termed excitotoxicity. Consistent with this concept, injection of glutamate receptor agonists, such as kainate (KA), into the CNS induces neurodegeneration similar to that seen in various neurodegenerative pathologies (Coyle et al., 1978).

The downstream mechanisms of excitotoxic neurodegeneration are complex, and many factors may contribute. One process that is associated with cell death after ischemic stroke or epilepsy is

\footnotetext{
Received June 15, 1999; revised Aug. 23, 1999; accepted Sept. 1, 1999.

This work was supported by Human Frontier Science Program Fellowship LT0486 to Z.-L.C., National Institutes of Health Grants NS-35704 and NS-38472, and American Cancer Society Grant CB205 to S.S. We are grateful to Dr. Fernando Sallés for comments on this manuscript. Z.-L.C. thanks all of the members of the Strickland laboratory for their support.

Correspondence should be addressed to Sidney Strickland, Department of Pharmacology, University at Stony Brook, Stony Brook, NY 11794-8651. E-mail: sid@pharm.sunysb.edu.

Copyright (C) 1999 Society for Neuroscience $\quad 0270-6474 / 99 / 199813-08 \$ 05.00 / 0$
}

the breakdown of the blood-brain barrier (BBB), which allows plasma proteins to leak into the brain parenchyma (Ting et al., 1986; Duncan and Todd, 1991). Although there is a good correlation between neuronal degeneration and BBB breakdown, it has not been determined whether either process is dependent on the other. That is, does neuronal death require BBB breakdown, or conversely, does neuronal death significantly contribute to leakage of plasma proteins?

To address this question, we have used various approaches. Our results indicate that neuronal death and BBB breakdown are independent of each other. This work has implications for the treatment of neurodegenerative disorders and other CNS pathologies.

\section{MATERIALS AND METHODS}

Intrahippocampal injections. Adult male wild-type mice, tissue plasminogen activator (tPA)-deficient (tPA ${ }^{-1-}$ ) mice (Carmeliet et al., 1994), plasminogen-deficient $\left(\mathrm{plg}^{-/-}\right)$mice (Bugge et al., 1995), or plasminogen-heterozygous ( $\mathrm{plg}^{+/-}$) mice (Bugge et al., 1995) were injected intraperitoneally with atropine $(0.6 \mathrm{mg} / \mathrm{kg}$ of body weight $)$ and then were anesthetized deeply with $2.5 \%$ avertin $(0.02 \mathrm{ml} / \mathrm{gm}$ of body weight). They were placed in a stereotaxic apparatus and injected unilaterally with 1.5 or $0.5 \mathrm{nmol}$ of kainate (Sigma, St. Louis, MO or Alexis, San Diego, CA) in $0.3 \mu$ l of PBS into the hippocampus (Andersson et al., 1991; Tsirka et al., 1995). After variable lengths of time, the animals were anesthetized and perfused through the heart with ice-cold PBS, followed by $4 \%$ paraformaldehyde in $0.1 \mathrm{M}$ PBS. The brains were removed, post-fixed in the same fixative overnight at $4^{\circ} \mathrm{C}$, and then left in $30 \%$ sucrose in PBS for $48 \mathrm{hr}$ at $4^{\circ} \mathrm{C}$. Coronal brain sections $(30 \mu \mathrm{m})$ were cut on a microtome, collected in $10 \mathrm{~mm}$ PBS, and then processed for cresyl violet staining and immunohistochemistry. For cresyl violet staining, the sections were mounted onto slides, dehydrated, and then stained with cresyl violet, which stains rough endoplasmic reticulum in neuronal cell bodies.

Intrahippocampal infusions. To obtain autologous plasma for infusion, $\sim 200 \mu \mathrm{l}$ of blood was collected from the femoral vein under anesthesia 
and immediately centrifuged at $7000 \mathrm{rpm}$ for $5 \mathrm{~min}$ at $4^{\circ} \mathrm{C}$. The plasma samples were stored at $-70^{\circ} \mathrm{C}$, recentrifuged, and diluted 1:1 in PBS before use. The mice were allowed to recover for 1 week before intrahippocampal infusion. Plasminogen was purified from human plasma (Deutsch and Mertz, 1970) and characterized by SDS-PAGE and casein zymography (data not shown). For the infusion, $\mathrm{plg}^{-1-}$ or wild-type mice were anesthetized as above and placed in a stereotaxic apparatus, and a micro-osmotic pump (Alza, Palo Alto, CA) containing $100 \mu \mathrm{l}$ of PBS (for three wild-type and three $\mathrm{plg}^{-1-}$ control mice infusion), $100 \mu \mathrm{l}$ of 1 $\mathrm{mg} / \mathrm{ml}$ human plasminogen in PBS (for four $\mathrm{plg}^{-1-}$ mice infusion), or $100 \mu \mathrm{l}$ of autologous plasma (for six wild-type mice infusion) was placed subcutaneously on the back of the animals. A brain infusion cannula connected to the pump was positioned at coordinates bregma $-2.5 \mathrm{~mm}$, mediolateral $0.5 \mathrm{~mm}$, and dorsoventral $1.6 \mathrm{~mm}$ to deliver the compound near the midline. The inf usion rate was $0.5 \mu \mathrm{l} / \mathrm{hr}$. The pump was allowed to inf use the designated solution for $2 \mathrm{~d}$, and kainate or PBS (for control) was then injected as described above. One or $2 \mathrm{~d}$ after kainate injection, the mice were killed, and their brains were examined for neuronal degeneration and processed for immunohistochemistry.

Intravenous injections. For intravenous injection, $\mathrm{plg}^{-1-}$ mice were anesthetized with avertin, and their right side femoral vein was exposed and injected with $0.2 \mathrm{ml}$ of $5 \mathrm{mg} / \mathrm{ml}$ human plasminogen solution (plasminogen purified as described above; $n=4)$. In control animals $(n=3)$, $0.2 \mathrm{ml}$ of vehicle (PBS) was injected. Within $15 \mathrm{~min}$, kainate was injected. At $0.5,2,8$, and $24 \mathrm{hr}$ after intravenous plasminogen injection, blood samples were collected from the tails and mixed with an equal volume of $250 \mathrm{~mm}$ sodium citrate, and plasma was prepared by centrifugation at $7000 \mathrm{rpm}$ for $5 \mathrm{~min}$.

Zymography. Five microliters of each plasma sample (prepared as above) or $0.7 \mu \mathrm{g}$ of human plasminogen was electrophoresed on a $10 \%$ SDS- polyacrylamide gel. After electrophoresis, the gel was washed in $2.5 \%$ Triton X-100 for $20 \mathrm{~min}$, followed by three rinses of $10 \mathrm{~min}$ each in water. The gel was overlaid on a substrate composed of $2.5 \%$ nonfat milk, $0.1 \mathrm{~m}$ Tris, $1 \%$ low-melting point agarose, $0.1 \%$ sodium azide, $2.25 \mathrm{mg} / \mathrm{ml}$ protein from mouse hippocampal extract (as a source of mouse tPA) (Sappino et al., 1993), and $1 \mathrm{~mm}$ amiloride (an inhibitor of urokinasetype plasminogen activator) (Vassali and Belin, 1987). The gel with the substrate underlay was then incubated at $37^{\circ} \mathrm{C}$ in a humid chamber for $24-48 \mathrm{hr}$ and photographed.

Immunohistochemistry. Mouse brain sections, manipulated as described above, were incubated with affinity-purified rabbit anti-mouse laminin polyclonal antibody (Sigma) at 1:1000 dilution or goat antihuman plasminogen antibody (Sigma) at 1:100 dilution at $4^{\circ} \mathrm{C}$ overnight. Biotinylated secondary antibodies were used at 1:200 dilution (Vector Laboratories, Burlingame, CA), and the avidin-biotin-peroxidase complex (ABC reaction) was visualized with diaminobenzidine and hydrogen peroxide. For IgG extravasation detection, brain sections were incubated with biotinylated goat anti-mouse IgG antibody (Vector Laboratories) at 1:200 dilution and visualized as described above. After anti-mouse IgG staining, some brain sections were counterstained with cresyl violet.

Quantitation of neuronal loss in the hippocampus. $\mathrm{Plg}^{-1-}$ mice were infused into the hippocampus with PBS $(n=3)$ or human plasminogen $(n=4)$, or injected intravenously with PBS $(n=3)$ or human plasminogen $(n=4)$ and then injected with kainate $(1.5 \mathrm{nmol})$. As control, $\mathrm{plg}^{+/-}$mice were also injected with kainate. For autologous plasma experiments, wild-type mice were inf used with autologous plasma $(n=$ $6)$ or PBS $(n=3)$ and then injected with kainate $(0.5 \mathrm{nmol}$; three PBS-infused and three plasma-infused mice) or PBS (three plasmainfused mice). Their brains were processed as above, and serial sections of $30 \mu \mathrm{m}$ were cut and stained with cresyl violet. Given the dramatic neuronal loss in the hippocampus in these experiments, we used camera lucida tracings to quantitate the number of neurons remaining (Tsirka et al., 1995, 1997). Four sections from the hippocampus of each mouse in each group were matched, and the linear lengths of dead pyramidal cell layers were determined on each section. The lengths were quantitated from camera lucida drawings of the hippocampus. The values for each category were averaged across the subjects in a group using the SigmaPlot program (Jandel Scientific, Corte Madera, CA).
KA injection

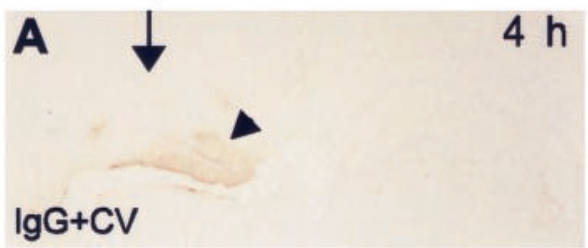

KA injection

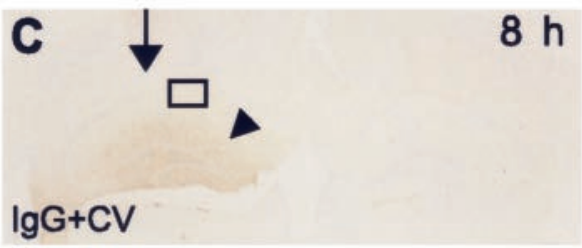

KA injection cresyl violet counterstaining $(A, C, E)$ or anti-laminin immunostaining $(B, D, F)$. Higher magnification of the boxed areas in $C$ and $E$ are shown in $G$ and $H$, respectively. At 4 and $8 \mathrm{hr}$ after kainate injection, plasma proteins as indicated by IgG immunostaining (arrowheads indicate IgGstained areas in $A$ and $C$ ) have not yet leaked into the CA1 region of the hippocampus $(A, C, G)$, but laminin is already degraded $(B, D)$ and the neurons are dying $(G)$. The color difference between $G$ and $H$ is a result of the increased $\operatorname{IgG}$ staining in $H$. IgG+CV, Anti-mouse IgG immunostaining counterstained lightly with cresyl violet; $L N$, anti-laminin immunostaining; arrows, kainate injection sites; arrowheads, anti-mouse $\operatorname{IgG}$ positively stained areas. Scale bars: $A-F, 1 \mathrm{~mm} ; G, H, 50 \mu \mathrm{m}$.

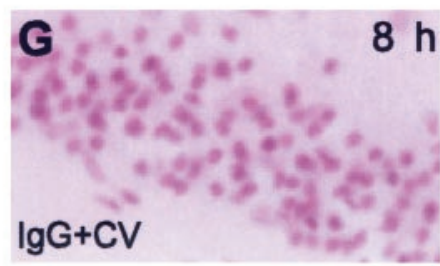

$24 \mathrm{~h}$

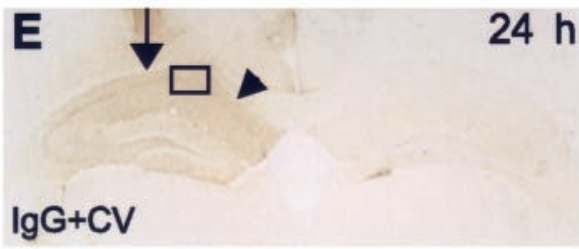

$8 \mathrm{~h}$
KA injection

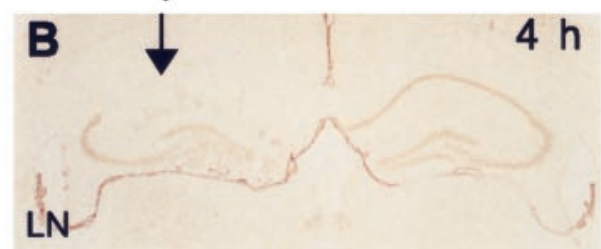

KA injection

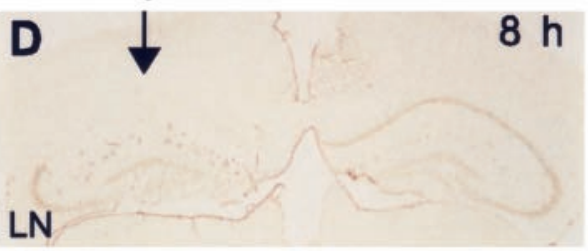

KA injection

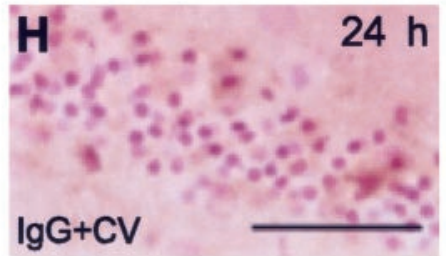

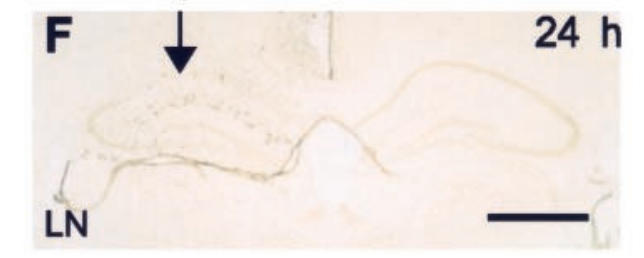




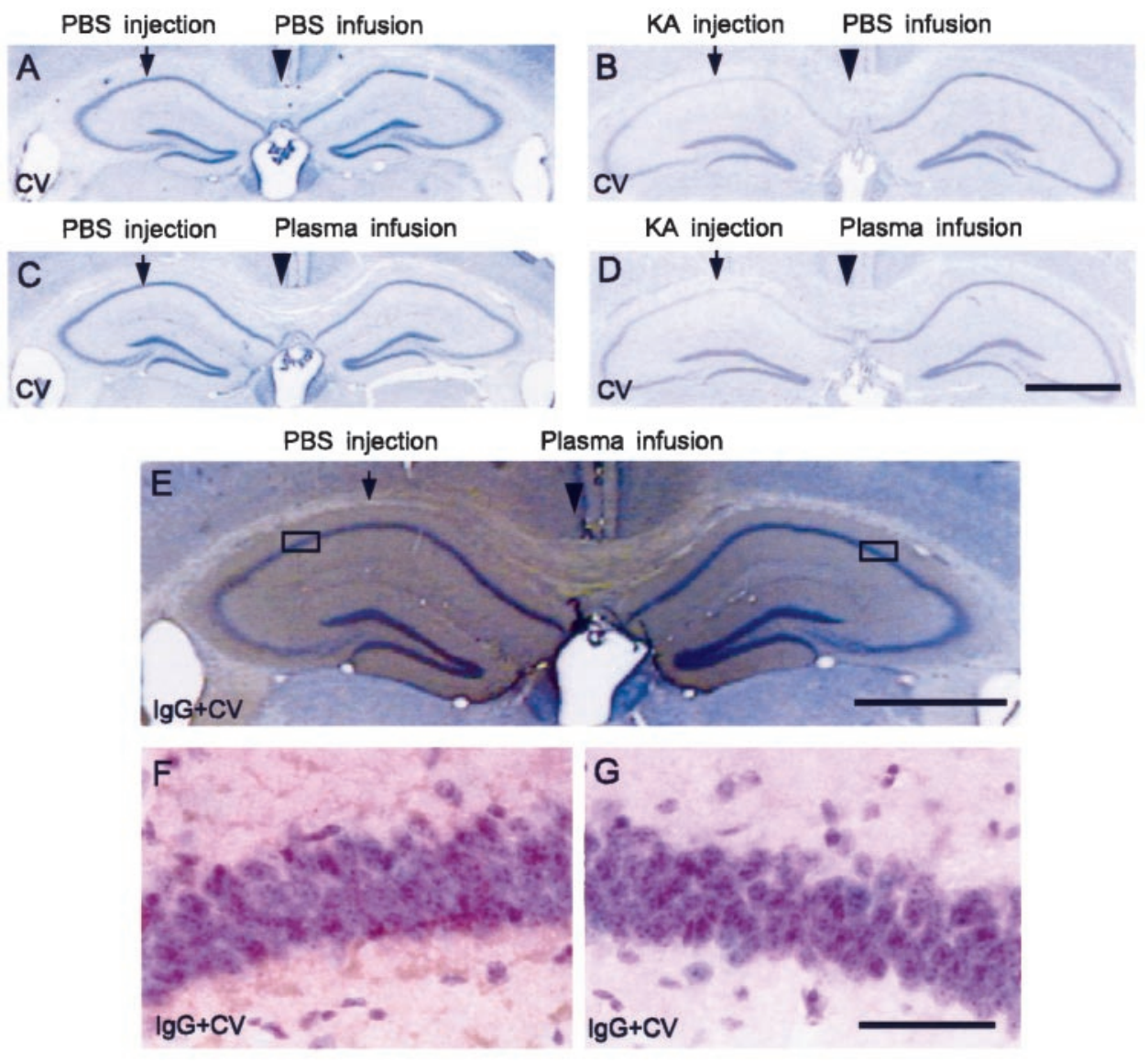

Figure 2. Autologous plasma is not toxic to hippocampal neurons and does not affect kainate-induced neuronal degeneration. Wild-type mice were infused with PBS or autologous plasma for $2 \mathrm{~d}$, and then PBS or kainate $(0.5 \mathrm{nmol})$ was injected unilaterally as indicated. Two days after kainate injection, the mice were killed, and brain sections were stained with cresyl violet $(A-D)$ or anti-mouse $\operatorname{IgG}$ immunostaining with cresyl violet counterstaining $(E)$. Intrahippocampal infusion of plasma does not cause neurodegeneration (compare $C, A$ ) and also does not affect kainate-induced neurodegeneration (compare $D, B$ ). The plasma infusions were efficient, as indicated by the brown color of the IgG staining $(E)$. Higher magnification of the boxed areas in $E$ are shown in $F$ and $G$. The neurons in the most efficiently infused area $(F)$ show no detectable morphological changes when compared with those in less efficiently infused area $(G)$. The brown staining in $F$ is contributed by high concentration of IgG accumulated in this area, which indicates the efficiency of plasma protein diffusion. The IgG concentration in the area shown in $G$ is very low and appears only as weak background color. $C V$, Cresyl violet staining; $\operatorname{IgG}+C V$, anti-mouse $\operatorname{IgG}$ immunostaining with cresyl violet counterstaining. Scale bars: $A-E, 1 \mathrm{~mm} ; F, G, 50 \mu \mathrm{m}$.

\begin{tabular}{|c|c|}
\hline Infusion/injection & $\begin{array}{l}\% \text { length of hippocampal neuronal } \\
\text { cell layer lost after injections }\end{array}$ \\
\hline Plasma/PBS $(n=3)$ & 0 \\
\hline PBS/kainate $(0.5 \mathrm{nmol} ; n=3)$ & $54.4 \pm 6.8 \%$ \\
\hline Plasma/kainate $(0.5 \mathrm{nmol} ; n=3)$ & $53.8 \pm 2.6 \%$ \\
\hline
\end{tabular}

\section{RESULTS}

\section{BBB leakage after kainate injection occurs too late to initiate neurodegeneration and laminin degradation}

As a first test of the role of BBB breakdown in hippocampal neuronal death, we examined the time course of plasma protein leakage after kainate injection in wild-type mice using $\mathrm{IgG}$ extravasation as an indicator. $\mathrm{IgG}$ is present at high levels in plasma $(550-1900 \mathrm{mg} / \mathrm{dl})$ and is easy to detect. For these reasons, the presence of $\mathrm{IgG}$ in the brain parenchyma has been used to monitor protein extravasation and disruption of the BBB (Ruth and Feinerman, 1988). At 4, 8, and $24 \mathrm{hr}$ after intrahippocampal kainate injection, mice were transcardially perfused, and their brains were stained for mouse IgG. At $4 \mathrm{hr}$, there was no detectable IgG leakage into the CA1 region of the hippocampus (Fig. $1 A$ ). However, laminin immunostaining, the loss of which is correlated with neuronal death (Chen and Strickland, 1997), was considerably decreased (Fig. $1 B$ ). At $8 \mathrm{hr}$, IgG leakage was still not detectable in the CA1 region (Fig. $1 C$ ), but the CA1 pyramidal neurons in the kainate-injected side exhibited pyknotic mor- phology characteristic of cell death (Fig. $1 G$ ), and laminin immunostaining remained approximately the same as at $4 \mathrm{hr}$ in the kainate-injected side (Fig. 1D). At $24 \mathrm{hr}$, IgG leakage was dramatically increased (Fig. $1 E$ ), and again laminin staining was similar as at the $4 \mathrm{hr}$ time point (Fig. $1 B, F$ ). One possibility was that this breakdown might be a consequence of neuronal degeneration, because it occurs after neurons in the kainate-injected side are undergoing degeneration (Fig. $1 G, E, H$ ). However, experiments shown below argue against this interpretation.

Because BBB dysfunction is not detectable in the hippocampal CA1 region until significant neuronal degeneration has already ensued, BBB breakdown appears to occur too late to be an initiator of neuronal damage.

\section{Plasma infused into the hippocampus is not toxic and does not affect excitotoxin-induced neuronal death}

Although the staining for $\mathrm{IgG}$ suggested that plasma proteins were not initiating neuronal degeneration, it was possible that concentrations too low to be detected by immunostaining were playing a role. To test this possibility, blood was collected from a mouse, plasma was prepared, and the autologous plasma was inf used into the hippocampus of the same mouse, with or without an accompanying submaximal kainate injection. If plasma proteins are neurotoxic by themselves, there should be some signs of neuronal damage without kainate injection. Likewise, if plasma proteins can exacerbate excitotoxin-induced neurodegeneration, kainate injection should promote more neurodegeneration when compared with control mice. However, our results showed that plasma infusion was not toxic to hippocampal neurons (Fig. $2 A, C, E-G$; Table 1$)$ and that previous infusion of autologous plasma did not exacerbate or attenuate kainate-induced neuronal 


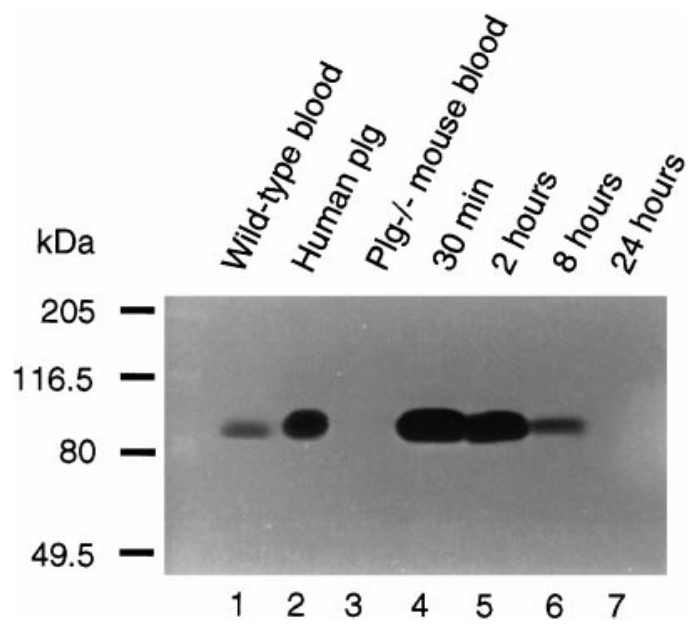

Figure 3. Zymographic analysis of the activation of human plasminogen by mouse tPA. Wild-type mouse blood and a sample of human plasminogen were assayed for activation by mouse tPA. The amount of mouse plasminogen in lane 1 was $\sim 0.3 \mu \mathrm{g}$, and the amount of human plasminogen in lane 2 was $\sim 0.7 \mu \mathrm{g}$. Mouse tPA activated both samples of plasminogen showing that the human protein is a substrate for mouse tPA. In addition, plasma was collected from $\mathrm{plg}^{-/-}$mice before or after intravenous plasminogen injection at the indicated time points. The plasminogen activity in the samples was visualized as described in Materials and Methods. There is no detectable plasminogen activity in $\mathrm{plg}^{-/-}$ mice before injection (lane 3), but it is present at concentrations greater or equal to that of wild-type mice until $8 \mathrm{hr}$ after injection (compare lanes 4-6 with lane 1). Protein molecular weight standards are indicated to the left.

death (Fig. 2B,D; Table 1). This result shows that plasma is not toxic to hippocampal neurons and further suggests that $\mathrm{BBB}$ breakdown is not a major factor in excitotoxic cell death.

\section{Intrahippocampal infusion of plasminogen rescues neuronal sensitivity to excitotoxin-induced degeneration in plg $^{-/-}$mice}

An extracellular protease cascade involving tPA and plasmin participates in excitotoxin-induced neurodegeneration (Tsirka et al., 1995, 1997; Strickland et al., 1996; Wang et al., 1998). In this model of degeneration, excess neuronal depolarization increases the release and synthesis of tPA in the hippocampus (Qian et al., 1993; Gualandris et al., 1996; Parmer et al., 1997; Baranes et al., 1998). This protease activates plasminogen to plasmin (Tsirka et al., 1997), which then initiates laminin degradation (Chen and Strickland, 1997). Loss of laminin-mediated interaction destabilizes neurons and is an important factor in promoting neuronal cell death. Pharmacological blockade of plasmin or genetic deficiency in either tPA or plasminogen makes mice resistant to neuronal cell death (Tsirka et al., 1995, 1997; Chen and Strickland, 1997).

Plasminogen is a serum protease whose primary role is fibrinolysis (Bugge et al., 1996). It is present at high levels in the blood ( $\sim 13 \mathrm{mg} / \mathrm{dl}$ ) (Lijnen et al., 1996) and is also synthesized by hippocampal neurons (Tsirka et al., 1997) in which its mRNA and protein levels are increased after kainate injection (Tsirka et al., 1997; Matsuoka et al., 1998). Excitotoxin injection causes BBB dysfunction (Saija et al., 1992; Bolton and Perry, 1998), resulting in leakage of plasma proteins into the brain parenchyma that might contribute to neuronal damage (Ruth, 1986). Therefore, the plasminogen needed to promote neuronal excitotoxic death in the hippocampus could be derived from local CNS synthesis or from extravasation through a compromised BBB.
We investigated this question by using $\mathrm{plg}^{-1-}$ mice (Bugge et al., 1995; Ploplis et al., 1995), which are viable and whose neurons are resistant to excitotoxin-induced neuronal death (Tsirka et al., 1997). The experimental strategy was to reconstitute CNS or vascular sources of plasminogen, through either intrahippocampal infusion or intravenous injection, respectively. For intrahippocampal infusion, plasminogen was infused for $2 \mathrm{~d}$ before kainate was injected into the hippocampus. The infusion was then continued for an additional $24 \mathrm{hr}$, and neuronal degeneration was determined. For intravenous injection, a bolus of plasminogen was injected just before hippocampal injection of kainate. After $24 \mathrm{hr}$, neuronal degeneration was determined. The extent of degeneration in these two protocols would reveal the relative contribution of CNS and vascular plasminogen to excitotoxininduced neuronal death.

To obtain sufficient quantities of plasminogen, human plasma was used for protein purification. By zymographic assay, we found that mouse tPA could efficiently activate human plasminogen (Fig. 3, lanes 1, 2).

To determine whether the kainate-resistant phenotype of $\mathrm{plg}^{-1-}$ mice could be rescued by intrahippocampal infusion of plasminogen, either PBS or plasminogen was infused into the hippocampus of $\mathrm{plg}^{-1-}$ mice, and then kainate was injected. Their brains were then examined for neurodegeneration. The PBS-infused mice showed resistance to neuronal cell death, consistent with previous observations (Tsirka et al., 1997) (Fig. 4A; Table 2). In contrast, plasminogen-infused mice exhibited dramatically increased neuronal degeneration (Fig. 4C; Table 2). Furthermore, in PBS-infused $\mathrm{plg}^{-/-}$mice, hippocampal laminin immunostaining was almost intact (Fig. 4B), whereas in plasminogen-infused mice, it was dramatically decreased (Fig. $4 D)$. Therefore, the resistance of $\mathrm{plg}^{-/-}$mice to excitotoxininduced neurodegeneration can be rescued by local plasminogen reconstitution. This result also demonstrates that human plasminogen can be efficiently activated by murine tPA in vivo. To determine the extent of plasminogen infusion, brain sections were stained with anti-plasminogen antibody. This staining showed that the infused plasminogen diffused efficiently to both sides of the hippocampus (Fig. $4 E$ ), but neuronal degeneration occurs only on the kainate-injected side (Fig. $4 C$ ), indicating that plasminogen is not toxic by itself.

\section{Intravenous injection of plasminogen into $\mathrm{plg}^{-/-}$mice does not restore neuronal sensitivity to excitotoxin}

To determine whether vascular plasminogen derived from BBB disruption could also contribute to excitotoxin-induced neurodegeneration, we injected plasminogen intravenously into $\mathrm{plg}^{-/-}$ mice to reconstitute the vascular source of plasminogen. Previous results showed that intravenous injection of $1 \mathrm{mg}$ of plasminogen is sufficient to restore thrombolytic potential in $\mathrm{plg}^{-/-}$mice (Lijnen et al., 1996). We therefore used this dose in our experiments. Within 15 min of intravenous PBS (control) or plasminogen injection, the mice were intrahippocampally injected with kainate. One day later, the brains were processed to determine neurodegeneration. $\mathrm{Plg}^{-/-}$mice injected intravenously with buffer (Fig. $5 A$ ) or plasminogen (Fig. $5 C$ ) both showed no significant hippocampal neuronal loss (Table 2), and laminin expression showed minimal changes in both groups of mice (Fig. $5 B, D$ ), indicating that intravenous plasminogen cannot restore the wildtype phenotype.

One reason that the intravenous plasminogen injection did not promote hippocampal neurodegeneration could be because of 

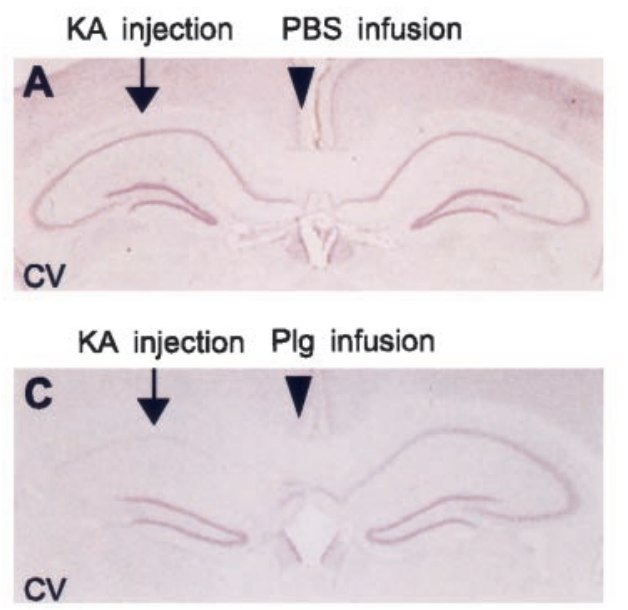

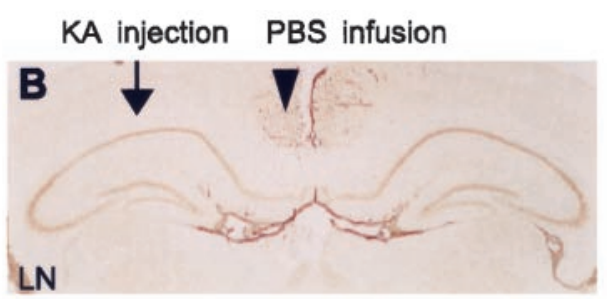

KA injection $\mathrm{Plg}$ infusion
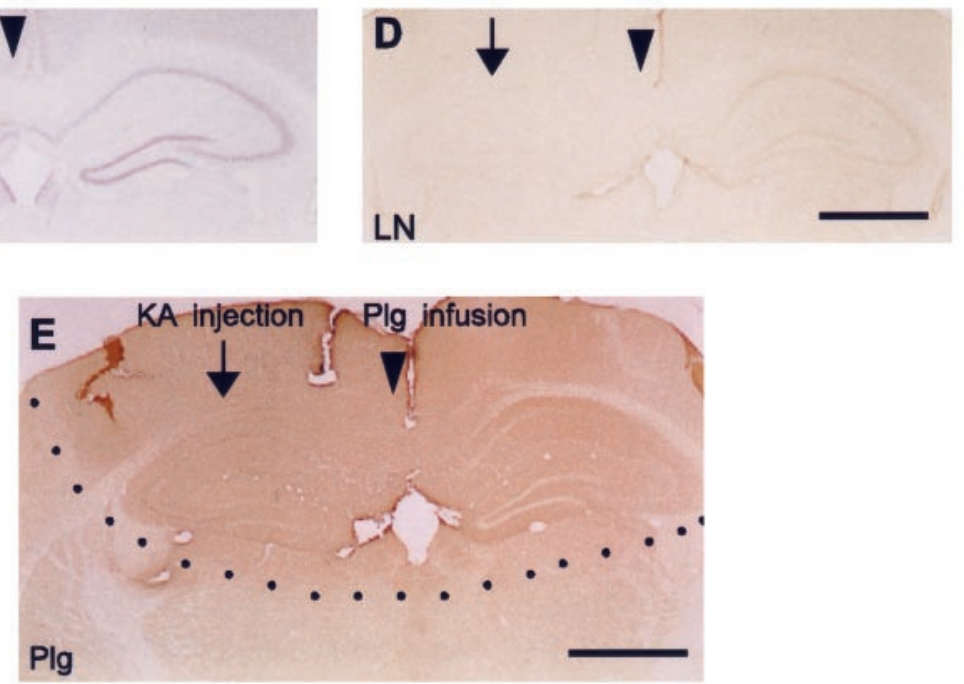

Figure 4. Intrahippocampal infusion of plasminogen restores neuronal sensitivity of $\mathrm{plg}^{-1-}$ mice to excitotoxin. Coronal brain sections through the hippocampus of $\mathrm{plg}^{-1-}$ mice treated as indicated in each panel were stained using cresyl violet $(A$, $C)$, anti-laminin immunostaining $(B, D)$, or anti-plasminogen immunostaining $(E)$. PBS-infused mice were resistant to kainate-induced neurodegeneration $(A)$ and laminin degradation $(B)$, but plasminogen-infused mice were sensitive to neurodegeneration and laminin degradation. The efficiency of plasminogen infusion was shown by plasminogen antibody immunostaining (brown in $E$ ). $C V$, Cresyl violet staining; $L N$, laminin immunostaining; $\mathrm{Plg}$, plasminogen immunostaining; $a r$ rows, kainate injection sites; arrowheads, PBS or plasminogen infusion sites. The dotted area in $E$ indicates the boundary of plasminogen diffusion. Scale bar, $1 \mathrm{~mm}$.

\begin{tabular}{l}
$\begin{array}{l}\text { Table 2. The effect of exogenous administration of plasminogen on } \\
\text { neuronal sensitivity to excitotoxin in } \mathbf{~ p l g}^{-1-} \text { mice }\end{array}$ \\
$\begin{array}{ll}\% \text { length of hippocampal } \\
\text { neuronal cell layer lost } \\
\text { after kainate injection } \\
(1.5 \mathrm{nmol})\end{array}$ \\
$\begin{array}{ll}\text { Genotype or treatment } & 86.8 \pm 6.4 \% \\
\mathrm{Plg}^{+/-} \text {heterozygotes }(n=5) & 7.1 \pm 3.6 \% \\
\mathrm{Plg}^{-/-} \text {mice } & 81.9 \pm 2.3 \% \\
\text { PBS intracerebral infusion }(n=3) & 5.2 \pm 1.5 \% \\
\text { Plg intracerebral infusion }(n=4) & 7.4 \pm 2.2 \% \\
\text { PBS IV injection }(n=3) & \text { Plg IV injection }(n=4)\end{array}$ \\
\hline
\end{tabular}

subthreshold levels of plasminogen in the blood after intravenous injection. In this case, even if the $\mathrm{BBB}$ was compromised, there would not be sufficient plasmin activity to catalyze hippocampal laminin degradation and promote neuronal death. Therefore, we obtained blood samples from $\mathrm{plg}^{-/-}$mice at various time points after intravenous plasminogen injection and analyzed blood plasminogen levels by zymography. After intravenous plasminogen injection, $\mathrm{plg}^{-/-}$mice showed a higher blood plasmin activity at $30 \mathrm{~min}, 2 \mathrm{hr}$, and $8 \mathrm{hr}$ than that present in wild-type mice (Fig. 3) when activated by mouse tPA. This result shows that intravenous injection of plasminogen is sufficient to restore wild-type blood levels for at least $8 \mathrm{hr}$. Previous studies showed that laminin degradation, a hallmark of kainate-induced neurodegeneration, occurs within $2 \mathrm{hr}$ of excitotoxin injection (Chen and Strickland, 1997). Therefore, these results indicate that leakage of vascular plasminogen into the CNS via BBB dysfunction is not a critical factor in excitotoxic neurodegeneration.

\section{BBB breakdown occurs after kainate injection in $\mathrm{tPA}^{-1-}$} or plg $^{-/-}$mice in the absence of neuronal death

The above results showed that BBB breakdown is not a critical factor in promoting neuronal death during excitotoxic injury and occurs after the initiation of laminin degradation and neurodegeneration. These results raise the possibility that BBB breakdown could be a consequence of neurodegeneration or a parallel pathological change. To address this question, we analyzed BBB breakdown after kainate injection in $\mathrm{tPA}^{-1-}$ or $\mathrm{plg}^{-1-}$ mice, whose neurons are resistant to degeneration (Tsirka et al., 1995, 1997). Although the neurons in $\mathrm{tPA}^{-1-}$ or $\mathrm{plg}^{-/-}$mice are resistant to degeneration after kainate injection (Fig. 6 compare $B, D$ with $F$ ), BBB breakdown occurred to a similar extent as in wild-type mice (Fig. 6A,C,E). This result indicates that $\mathrm{BBB}$ breakdown is not a direct consequence of neurodegeneration. Because BBB breakdown occurs after kainate injection in $\mathrm{PA}^{-/-}$ or $\mathrm{plg}^{-/-}$mice but the neurons are spared, this result suggests neuronal death during acute excitotoxic injury is not required for BBB breakdown.

\section{DISCUSSION}

Various pathologies can affect BBB function, including brain tumors (Roelcke et al., 1995), bacterial meningitis (Paul et al., 1998), and multiple sclerosis (Kwon and Prineas, 1994). One dramatic example is the brain edema that results from cerebral ischemia (Wahl et al., 1990; Preston et al., 1993) and excitotoxic injury (Lassmann et al., 1984; Seitelberger et al., 1990). Although BBB dysf unction has long been associated with neuronal damage after excitotoxic injury (Ruth, 1986; Ting et al., 1986), a direct connection between these two events has not been established (Rapaport and Thompson, 1975; Kuroiwa et al., 1985; Bolton and Perry, 1998). For example, Bolton and Perry (1998) found that, although juvenile animals exhibited greater BBB breakdown after 
Figure 5. Intravenous bolus injection of human plasminogen does not restore neuronal sensitivity of $\mathrm{plg}^{--}$mice to excitotoxin. Cresyl violet $(A, C)$ or anti-laminin immunostained $(B, D)$ coronal brain sections through the hippocampus of $\operatorname{PBS}(A, B)$ or plasminogen $(C, D)$ intravenously injected $\mathrm{plg}^{-1-}$ mice 24 $\mathrm{hr}$ after kainate injection. Both groups of mice are resistant to neurodegeneration and laminin degradation. $C V$, Cresyl violet staining; $L N$, anti-laminin immunostaining; arrows, kainate injection sites. Scale bar, $1 \mathrm{~mm}$.
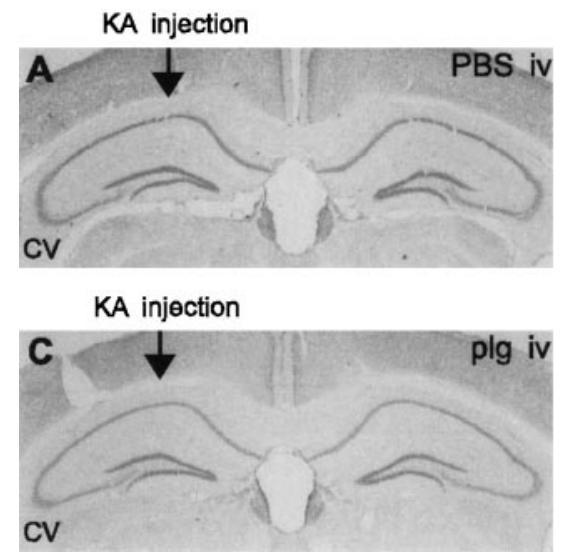
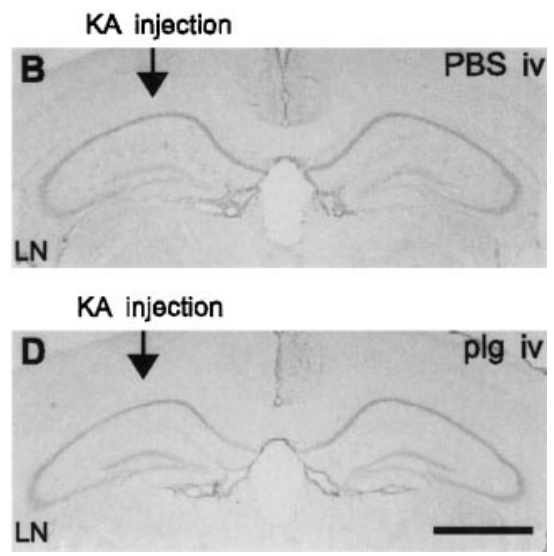

excitotoxin injection, lesion size and number of infiltrating leukocytes were similar when compared with the adult. Moreover, Rapaport and Thompson (1975) found that osmotic opening of $\mathrm{BBB}$ did not cause neurological deficits in monkey.

One direct consequence of BBB breakdown is plasma protein leakage into the brain parenchyma, which may cause edema, but the effect of this leakage on neurons and other CNS cells also remains an open question (Ikuta et al., 1983; Strosznajder et al., 1983; Ruth, 1986; Ting et al., 1986; Saija et al., 1992). Edema fluid has homeostatic properties (Ikuta et al., 1983), and albumin, a major plasma protein, can stimulate the incorporation of free arachidonic acid into brain phospholipids (Strosznajder et al., 1983) and therefore reduce neurotoxic free radical levels in the brain parenchyma. These findings argue against a direct acute contribution of $\mathrm{BBB}$ breakdown to neurodegeneration and neurotoxicity.

In our studies, we initially used two approaches to investigate the role of $\mathrm{BBB}$ breakdown in acute excitotoxicity. First, we compared the time course of plasma protein leakage and neuronal death after excitotoxin injection. These studies showed that the first significant BBB leakage occurs after neuronal death has already been initiated, which suggested that plasma proteins do not initiate the degeneration. Previously, a temporal analysis during transient focal ischemia showed that neuronal damage precedes $\mathrm{BBB}$ leakage; the authors of that study concluded that $\mathrm{BBB}$ dysfunction is unlikely to contribute to neuronal death (Albayrak et al., 1997).

Second, we directly infused plasma proteins into the brain parenchyma and showed that they are not toxic nor do they affect excitotoxin-induced death. To our knowledge, plasma has not been examined previously for its direct neurotoxic effects or its ability to modulate excitotoxic damage. However, autologous serum and rat albumin have been injected into the rat brain and neurotoxicity was observed (Hassel et al., 1994; Kadota et al., 1997). The difference in results between these studies and ours could be caused by a difference in protocols. Whereas we infused plasma at a rate of $0.5 \mu \mathrm{l} / \mathrm{hr}$ for $4 \mathrm{~d}$, the previous studies injected a $25 \mu \mathrm{l}$ volume of serum or albumin into the rat brain in a shorter time (Hassel et al., 1994; Kadota et al., 1997). It is possible that the large volume injection coupled with increased fluid extravasation attributable to protein osmotic effects could have contributed to edema-mediated neuronal death in those studies.
Figure 6. BBB breakdown occurs in the absence of neuronal death after kainate injection in $\mathrm{tPA}^{-1-}$ or $\mathrm{plg}^{-1-}$ mice. Coronal brain sections through the hippocampus of $\mathrm{tPA}^{-1-}$, $\mathrm{plg}^{-/-}$, or wild-type mice $2 \mathrm{~d}$ after kainate injection were stained with anti-mouse $\mathrm{IgG}$ antibody $(A, C, E)$ or cresyl violet $(B, D, F)$. BBB breakdown after kainate injection is equivalent in $\mathrm{tPA}^{-1-}, \mathrm{plg}^{-1-}$, or wild-type mice as evidenced by anti-mouse IgG staining (diff use dark area in ipsilateral side, marked by arrowheads in $A, C, E$ ), whereas the $\mathrm{tPA}^{-1-}$ and $\mathrm{plg}^{-/-}$neurons are resistant to degeneration (compare $B, D$ with $F$ ). $C V$, Cresyl violet staining; $\operatorname{Ig} G$, anti-mouse $\operatorname{IgG}$ immunostaining; arrows, kainate injection sites; arrowheads, anti-mouse IgG positively stained areas. Scale bar, $1 \mathrm{~mm}$.
KA injection
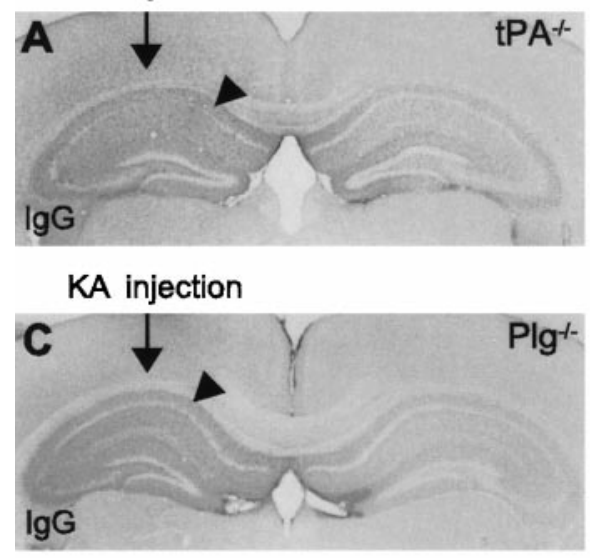

KA injection

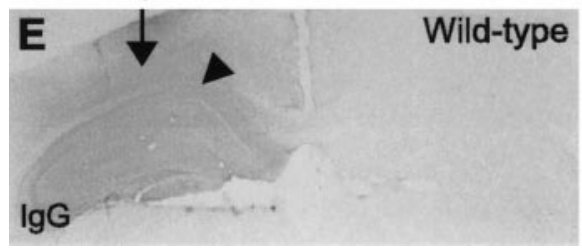

\section{KA injection}

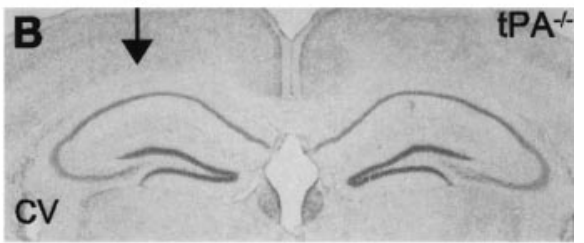

KA injection

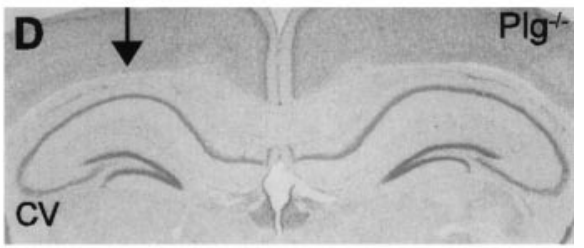

$\mathrm{KA}$ injection

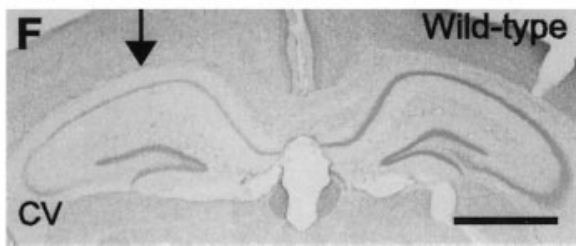


Although these two analyses argue against a role for $\mathrm{BBB}$ breakdown in neuronal death, there are caveats with this interpretation. In our time course study of BBB breakdown, we cannot rule out the possibility that undetectable amounts of plasma protein may be extravasating into the brain parenchyma and promoting neuronal death. Also, in our direct autologous plasma infusion experiment, the plasma protein may not be promoting a toxic effect because our delivery may not adequately mimic the accumulation that occurs after BBB breakdown.

Both of these caveats have been addressed by the use of the $\mathrm{plg}^{-/-}$mice. Because plasminogen is required for efficient excitotoxic killing and because the blood normally contains very high concentrations of this protein, the source of plasminogen could be leakage from the blood. Intrahippocampal infusion of plasminogen restored kainate sensitivity in $\mathrm{plg}^{-/-}$mice, whereas intravenous injection of plasminogen did not. This result, which uses proteolytic degradation of laminin and neuronal death as end points for the assay, indicates that plasma-derived plasminogen cannot fulfill the requirements for this protein in degeneration.

These analyses, coupled with previous evidence, argue that $\mathrm{BBB}$ breakdown and plasma protein leakage into the brain parenchyma after excitotoxic injury are not sufficient for neuronal death.

A second question concerns the mechanism of BBB breakdown. The properties of the $\mathrm{BBB}$ are contributed by the specialized endothelial cells of the CNS capillaries and the end feet of astrocytes that wrap the endothelial cells on the neuronal side. The endothelial cells of the CNS capillaries are distinct from those in other organs in that they are joined by tight junctions of high electric resistance, and there is also no transcellular movement of compounds through the CNS endothelial cells (Kandel et al., 1991; Bradbury, 1993). These properties provide the critical barrier that restricts the passage of vascular substances into the CNS.

Injection of glutamate analogs either systemically or intracerebrally can cause BBB breakdown in some regions of the brain, such as the hippocampus (Nitsch and Hubauer, 1986; Ruth, 1986; Ruth and Feinerman, 1988). This effect could be mediated on astrocytes and endothelial cells indirectly via effects of the excitotoxin on neurons, e.g., the neurons could release factors that influence astrocyte or endothelial function. Alternatively, glutamate analogs could affect these cells directly.

Glutamate receptors have been reported to be present on CNS endothelial cells and astrocytes (Steinhauser and Gallo, 1996; Krizbai et al., 1998). There is other evidence that astrocyte function, which forms an important functional component of BBB (Janzer and Raff, 1987), is adversely affected by excitotoxins. During ischemic injury, astrocyte interactions with the extracellular matrix are rapidly disrupted (Wagner et al., 1997), and deficits in astrocytes result in incomplete reconstruction of impaired BBB (Kakinuma et al., 1998). After kainate injection, a loss of GFAP staining, a marker of astrocytes, coincides with IgG extravasation (Bolton and Perry, 1998). An early massive swelling of astrocyte processes after kainate injection also occurs (Lassmann et al., 1986). The tight junctions of the CNS endothelial cells do not seem to be affected by excitotoxins, but transendothelial pinocytosis is increased by kainate injection (Nitsch and Hubauer, 1986). Therefore, astrocyte dysfunction coupled with increased transendothelial pinocytosis in the endothelial cells may contribute to BBB breakdown after excitotoxic injury.

To address this question, we analyzed BBB dysfunction in $\mathrm{tPA}^{-1-}$ or $\mathrm{plg}^{-1-}$ mice whose neurons are resistant to death after kainate injection. Our result shows that they exhibit BBB break- down after kainate injection. These results argue that the effect of kainate on the BBB is a direct result of effects on the astrocytes and endothelium, and they show that neuronal death is not required for $\mathrm{BBB}$ breakdown.

Pharmacological treatment of CNS pathologies is complicated by the inaccessibility of the region to intravenously administered agents. This problem has severely limited drug design and therapy into the CNS. One way to circumvent this difficulty would be to combine systemic treatments with a protocol that transiently opens the BBB. A concern of this approach is that opening the $\mathrm{BBB}$ could be deleterious to neurons in the CNS. However, our results indicate that in the absence of frank edema, plasma proteins do not cause significant neurodegeneration in the CNS, suggesting that the therapeutic strategy of opening the BBB might be more promising than previously realized.

\section{REFERENCES}

Albayrak S, Zhao Q, Siesjo BK, Smith ML (1997) Effect of transient focal ischemia on blood-brain barrier permeability in the rat: correlation to cell injury. Acta Neuropathol (Berl) 94:158-163.

Andersson PB, Perry VH, Gordon S (1991) The kinetics and morphological characteristics of the macrophage-microglial response to kainic acid-induced neuronal degeneration. Neuroscience 42:201-214.

Baranes D, Lederfein D, Huang YY, Chen M, Bailey CH, Kandel ER (1998) Tissue plasminogen activator contributes to the late phase of LTP and to synaptic growth in the hippocampal mossy fiber pathway. Neuron 21:813-825.

Bolton SJ, Perry VH (1998) Differential blood-brain barrier breakdown and leucocyte recruitment following excitotoxic lesions in juvenile and adult rats. Exp Neurol 154:231-240.

Bradbury MW (1993) The blood-brain barrier. Exp Physiol 78:453-472.

Bugge TH, Flick MJ, Daugherty CC, Degen JL (1995) Plasminogen deficiency causes severe thrombosis but is compatible with development and reproduction. Genes Dev 9:794-807.

Bugge TH, Kombrinck KW, Flick MJ, Daugherty CC, Danton MJ, Degen JL (1996) Loss of fibrinogen rescues mice from the pleiotropic effects of plasminogen deficiency. Cell 87:709-719.

Carmeliet P, Schoonjans L, Kieckens L, Ream B, Degen J, Bronson R, De Vos R, van den Oord JJ, Collen D, Mulligan RC (1994) Physiological consequences of loss of plasminogen activator gene function in mice. Nature 368:419-424.

Chen ZL, Strickland S (1997) Neuronal death in the hippocampus is promoted by plasmin-catalyzed degradation of laminin. Cell 91:917-925.

Coyle JT, Puttfarcken P (1993) Oxidative stress, glutamate, and neurodegenerative disorders. Science 262:689-695.

Coyle JT, Molliver ME, Kuhar MJ (1978) In situ injection of kainic acid: a new method for selectively lesioning neural cell bodies while sparing axons of passage. J Comp Neurol 180:301-323.

Deutsch DG, Mertz ET (1970) Plasminogen: purification from human plasma by affinity chromatography. Science 170:1095-1096.

Duncan R, Todd N (1991) Epilepsy and the blood-brain barrier. Br J Hosp Med 45:32-34.

Gualandris A, Jones TE, Strickland S, Tsirka SE (1996) Membrane depolarization induces calcium-dependent secretion of tissue plasminogen activator. J Neurosci 16:2220-2225.

Hassel B, Iversen EG, Fonnum F (1994) Neurotoxicity of albumin in vivo. Neurosci Lett 167:29-32.

Ikuta F, Yoshida Y, Ohama E, Oyanagi K, Takeda S, Yamazaki K, Watabe K (1983) Revised pathophysiology on BBB damage: the edema as an ingeniously provided condition for cell motility and lesion repair. Acta Neuropathol Suppl (Berl) 8:103-110.

Janzer RC, Raff MC (1987) Astrocytes induce blood-brain barrier properties in endothelial cells. Nature 325:253-257.

Kadota E, Nonaka K, Karasuno M, Nishi K, Teramura K, Hashimoto S (1997) Neurotoxicity of serum components, comparison between CA1 and striatum. Acta Neurochir Suppl (Wien) 70:141-143.

Kakinuma Y, Hama H, Sugiyama F, Yagami K, Goto K, Murakami K, Fukamizu A (1998) Impaired blood-brain barrier function in angiotensinogen-deficient mice. Nat Med 4:1078-1080.

Kandel ER, Schwartz JH, Jessell TM (1991) Principles of neural science, pp 1054-1056. New York: Elsevier. 
Krizbai IA, Deli MA, Pestenacz A, Siklos L, Szabo CA, Andras I, Joo F (1998) Expression of glutamate receptors on cultured cerebral endothelial cells. J Neurosci Res 54:814-819.

Kuroiwa T, Cahn R, Juhler M, Goping G, Campbell G, Klatzo I (1985) Role of extracellular proteins in the dynamics of vasogenic brain edema. Acta Neuropathol 66:3-11.

Kwon EE, Prineas JW (1994) Blood-brain barrier abnormalities in longstanding multiple sclerosis lesions. An immunohistochemical study. J Neuropathol Exp Neurol 53:625-636.

Lassmann H, Petsche U, Kitz K, Baran H, Sperk G, Seitelberger F, Hornykiewicz O (1984) The role of brain edema in epileptic brain damage induced by systemic kainic acid injection. Neuroscience 13:691-704.

Lassmann H, Baran H, Petsche U, Kitz K, Sperk G, Hornykiewicz O, Seitelberger F (1986) Ultrastructural analysis of rat brain tissue following systemic kainate administration. Adv Exp Med Biol 203:223-230.

Lijnen HR, Carmeliet P, Bouche A, Moons L, Ploplis VA, Plow EF, Collen D (1996) Restoration of thrombolytic potential in plasminogen-deficient mice by bolus administration of plasminogen. Blood 88:870-876.

Lipton SA, Rosenberg PA (1994) Excitatory amino acids as a final common pathway for neurologic disorders. N Engl J Med 330:613-622.

Matsuoka Y, Kitamura Y, Taniguchi T (1998) Induction of plasminogen in rat hippocampal pyramidal neurons by kainic acid. Neurosci Lett 252:119-122.

Meldrum B, Garthwaite J (1990) Excitatory amino acid neurotoxicity and neurodegenerative disease. Trends Pharmacol Sci 11:379-387.

Nitsch C, Hubauer H (1986) Distant blood-brain barrier opening in subfields of the rat hippocampus after intrastriatal injections of kainic acid but not ibotenic acid. Neurosci Lett 64:53-58.

Parmer RJ, Mahata M, Mahata S, Sebald MT, O'Connor DT, Miles LA (1997) Tissue plasminogen activator (t-PA) is targeted to the regulated secretory pathway. Catecholamine storage vesicles as a reservoir for the rapid release of t-PA. J Biol Chem 272:1976-1982.

Paul R, Lorenzl S, Koedel U, Sporer B, Vogel U, Frosch M, Pfister HW (1998) Matrix metalloproteinases contribute to the blood-brain barrier disruption during bacterial meningitis. Ann Neurol 44:592-600.

Ploplis VA, Carmeliet P, Vazirzadeh S, Van Vlaenderen I, Moons L, Plow EF, Collen D (1995) Effects of disruption of the plasminogen gene on thrombosis, growth, and health in mice. Circulation 92:2585-2593.

Preston E, Sutherland G, Finsten A (1993) Three openings of the bloodbrain barrier produced by forebrain ischemia in the rat. Neurosci Lett 149:75-78.

Qian Z, Gilbert ME, Colicos MA, Kandel ER, Kuhl D (1993) Tissueplasminogen activator is induced as an immediate-early gene during seizure, kindling an long-term potentiation. Nature 361:453-457.

Rapaport S, Thompson H (1975) Osmotic opening of the blood-brain barrier in the monkey without associated neurological deficits. Science 180:971.
Roelcke U, Radu EW, von Ammon K, Hausmann O, Maguire RP, Leenders KL (1995) Alteration of blood-brain barrier in human brain tumors: comparison of [18F]fluorodeoxyglucose, [11C]methionine and rubidium-82 using PET. J Neurol Sci 132:20-27.

Ruth RE (1986) Extravasated protein as a cause of limbic seizureinduced brain damage: an evaluation using kainic acid. Adv Exp Med Biol 203:211-221.

Ruth RE, Feinerman GS (1988) Foreign and endogenous serum protein extravasation during harmaline tremors or kainic acid seizures in the rat: a comparison. Acta Neuropathol 76:380-387.

Saija A, Princi P, Pisani A, Santoro G, De Pasquale R, Massi M, Costa G (1992) Blood-brain barrier dysf unctions following systemic injection of kainic acid in the rat. Life Sci 51:467-477.

Sappino A-P, Madani R, Huarte J, Belin D, Kiss JZ, Wohlwend A, Vassalli J-D (1993) Extracellular proteolysis in the adult murine brain. J Clin Invest 92:679-685.

Seitelberger F, Lassmann H, Hornykiewicz O (1990) Some mechanisms of brain edema studied in a kainic acid model. Acta Neurobiol Exp $50: 263-267$.

Shoulson I (1998) Experimental therapeutics of neurodegenerative disorders: unmet needs. Science 282:1072-1074.

Steinhauser C, Gallo V (1996) News on glutamate receptors in glial cells. Trends Neurosci 19:339-345.

Strickland S, Gualandris A, Rogove AD, Tsirka SE (1996) Extracellular proteases in neuronal function and degeneration. Cold Spring Harb Symp Quant Biol 61:739-745.

Strosznajder J, Foudin L, Tang W, Sun GY (1983) Serum albumin washing specifically enhances arachidonate incorporation into synaptosomal phosphatidylinositols. J Neurochem 40:84-90.

Ting P, Masaoka H, Kuroiwa T, Wagner H, Fenton I, Klatzo I (1986) Influence of blood-brain barrier opening to proteins on development of post-ischaemic brain injury. Neurol Res 8:146-151.

Tsirka SE, Gualandris A, Amaral DG, Strickland S (1995) Excitotoxininduced neuronal degeneration and seizure are mediated by tissue plasminogen activator. Nature 377:340-344.

Tsirka SE, Rogove AD, Bugge TH, Degen JL, Strickland S (1997) An extracellular proteolytic cascade promotes neuronal degeneration in the mouse hippocampus. J Neurosci 17:543-552.

Vassalli JD, Belin D (1987) Amiloride selectively inhibits the urokinasetype plasminogen activator. FEBS Lett 214:187-191.

Wagner S, Tagaya M, Koziol JA, Quaranta V, del Zoppo GJ (1997) Rapid disruption of an astrocyte interaction with the extracellular matrix mediated by integrin alpha 6 beta 4 during focal cerebral ischemia/reperfusion. Stroke 28:858-865.

Wahl M, Unterberg A, Baethmann A, Schilling L (1990) Mediators of vasogenic brain edema. J Basic Clin Physiol Pharmacol 1:221-233.

Wang YF, Tsirka SE, Strickland S, Stieg PE, Soriano SG, Lipton SA (1998) Tissue plasminogen activator (tPA) increases neuronal damage after focal cerebral ischemia in wild-type and tPA-deficient mice. Nat Med 4:228-231. 